Research Article

\title{
Study on Coordination and Optimization of Contract Farming Supply Chain Based on Uncertain Conditions
}

\author{
Xinquan Liu $\mathbb{D}^{1},{ }^{1}$ Xiaojing Shen $\mathbb{D}^{1},{ }^{1}$ and Ming You ${ }^{2}$ \\ ${ }^{1}$ School of Logistics Management and Engineering, Nanning Normal University, Nanning, Guangxi 530001, China \\ ${ }^{2}$ Office of Human Resources, Nanning Normal University, Nanning, Guangxi 530001, China \\ Correspondence should be addressed to Xiaojing Shen; 614243786@qq.com
}

Received 28 May 2020; Revised 19 June 2020; Accepted 29 June 2020; Published 20 July 2020

Academic Editor: Lu Zhen

Copyright (c) 2020 Xinquan Liu et al. This is an open access article distributed under the Creative Commons Attribution License, which permits unrestricted use, distribution, and reproduction in any medium, provided the original work is properly cited.

As the transaction subject of contract farming, agricultural products are featured with a long production cycle and a short sales cycle, just like other perishable commodities. In the process of executing a contract, both the company and the farmer are running the risk of great uncertainty. This paper studies the coordination of agricultural supply chain in terms of the uncertainty of agricultural output and market demand. First of all, the random output volatility factor and the market demand volatility factor as two random variables are used to represent the uncertainty of the agricultural output and market demand, and revenue functions are set up, respectively, for the company and the farmer with the objective of maximizing expected returns. The theoretical derivation of these revenue functions proves that there is an optimal targeted yield in a centralized decision-making supply chain system and a single optimal solution that maximizes farmers' revenue can be obtained in a decentralized one, but the centralized decision-making supply chain is superior to the decentralized and uncoordinated counterpart for overall benefit. Secondly, a revenue-sharing-plus-margin contract mechanism is proposed to coordinate income distribution between the two parties of the supply chain through the revenue-sharing coefficient and margin. Thirdly, calculation examples are given and solved by MATLAB based on the assumption that both the agricultural output volatility factor and the market demand volatility factor are uniformly distributed, and the theory and result are then verified consistently. Finally, the numerical analysis of the coordination mechanism of the revenue-sharing coefficient and the margin on both sides of the supply chain provides an optimal value range so that Pareto improvement on the company's and the farmers' income can be achieved.

\section{Introduction}

With the deepening reform of the agricultural product circulation system, the order-based agriculture supply chain has emerged and become prevailing in China since the 1990s. It is worth mentioning that the company-plussmallholder type has also gained its popularity as a basic business mode, which refers to an order contract signed by the company as the processing and sales party and the farmer as the producer before the production of agricultural products, where the two parties agree on the type, quantity, quality, purchase price, time, and place of agricultural products to be traded. Farmers grow crops and then both parties conduct spot transactions of the produce at the end of the production cycle in accordance with the order contract.
The order contract between companies and farmers represents the market demand which functions as a guide for farmers to planned farming in avoidance of blind production, achieving a dynamic connection between the production of smallholder farmers and market, which explains the reason why the order-based agriculture supply chain has been developing.

However, there are problems coming with the rise of the order-based agricultural supply chain, one of which is that the high default rate is highly detrimental to the stability and growth of this supply chain. Hobbs and Young [1] believed the main reason for this problem lied in the necessity of reducing transaction costs after a probe into the vertical coordination in the supply chain based on the transaction cost theory. Martinez [2] also utilized the 
theory to make an analysis on the influence factors of transaction cost which affect the order contract business mode of agricultural by-products and found that this mode was directly affected by asset specificity, product quality, and farmers' efforts. Guo and Jolly [3] found that the legal mechanism played a smaller role in improving contract performance than nonformal means on the basis of an investigation of order-based agriculture in Zhejiang Province, China. In terms of companies with dual-source raw materials and multiproduct combinations in the beef industry, Boyabatli et al. [4] assumed that long-term and short-term contract mechanisms could be adopted to improve their own effectiveness under specific circumstances. Based on the analysis of potato farmers' preference for given contract types in Ethiopia, Abebe et al. [5] found that the uncertainty of the import market rather than the export market was more likely to sway farmers' decision whether to be engaged in the business, and farmers were inclined to do business with buyers specialized in seeds, raw materials, and technical support from government and nongovernmental organizations in an attempt to reduce risks. Liu [6] made an analysis on the existing problems of sales contracts of in China led by the incomplete contract theory. They pointed out that the indeterminacy of contracts as well as the opportunism behavior tendency of both parties, namely, the incompleteness of contract caused by information asymmetry, is the root reason for the low-performance rate of sales contracts, and the market risks are proposed to be shouldered by both parties. Liu and Qi [7] applied transaction cost theory to make a quantitative analysis of the factors affecting the option of contracts between enterprises and farmers and proposed that the final contract solution should be bounded and acceptable to both parties so as to improve the stability and performance rate of contracts. Wu et al. [8] discussed the payment costs incurred by farmers and leading enterprises in different game behaviors under the conditions of good, medium, and bad market price fluctuations, proving that the increase of liquidated damages is a means to guarantee the stability of contracts. Fang [9] investigated the conditions for managing default risk under the order-plus-futures mode by establishing the market equilibrium model before and after the introduction of futures trading, which was thought to be conducive to stabilizing the spot price and improve the performance rate of contracts. Based on 381 pseudocopies of order contracts from Shaanxi Province, the research team of Xi'an Branch of the People's Bank of China [10] analyzed the factors affecting the contract performance rate under the direction of logistic and made a proposal that the contract performance rate could be raised by means of cultivating the order subject, standardizing the contract text and innovating financial products. Yang et al. [11] analyzed the default risk under different modes of contract farming, and the results showed that a higher conversion rate of agricultural products processing and default penalty coefficient contributed to increasing the performance rate of contracts.

As the transaction subject of contract farming, agricultural products are featured with a long production cycle and a short sales cycle, just like other perishable commodities. In the process of executing a contract, companies and farmers are both taking a great risk. The company will face market demand uncertainty if order contracts with farmers are signed before the production of agricultural products, while farmers will have to confront output uncertainty due to the adverse impact of environmental factors such as a terrible climate or pest disasters. Considering the weather problems encountered during the production of seasonal products, Chen and Yano [12-14] based on the measures of uncertainty put forward risk compensation to coordinate the contractual relationship between companies and farmers so as to ensure the stability of contract farming. Wang et al. [15] found through analysis that smallholders are expected to have independent management rights given their small size and poor resistance to risks, and they will only fulfill contracts if they are satisfied with existing transactions. On the premise of a uniform distribution of the fluctuation factors of yield and demand, Zhao and $\mathrm{Wu}$ [16] analyzed how to achieve the supply chain coordination of individual producers and retailers of produce and proposed that revenue-sharing contracts would be a solution. Ling et al. [17] put forward a solution that ensures a longterm cooperation between farmers and supermarkets under random yield and demand against the background of China's famer-to-supermarket mode. Liu and Xie [18] came up with a risk-sharing contract to cope with the coordination between manufacturers and retailers in the agriculture supply chain based on the uncertainty of yield and market demand. Sun and Xu [19] brought up a twotier supply chain model of agricultural products consisting of an individual supplier and retailer in a perfect competition market. And after studying option contracts in terms of stochastic supply and demand, they found better coordination of option contracts with the increased randomness of suppliers. Taking the company-plusfarmer order-based agriculture as the research object and the wholesale price of the traditional contract as the reference object, Qin and Teng [20] studied comprehensively the uncertain market demand faced by companies, the uncertain yield faced by farmers, and the fluctuations of wholesale price confronted by both parties and conducted an analysis of the performance of the supply chain after the implementation of the "Guaranteed Minimum Purchase and Following the Market" policy that was considered beneficial for farmers. Tong [21] analyzed the decision-making behavior of companies and farmers in terms of the price mechanism of traditional order-based agriculture under the conditions of random purchase prices and uncertain market demand and proposed a contract mechanism featured with revenue sharing plus two-way subsidy plus franchise fee to promote the coordination of order agriculture supply chain.

Referring to the above-mentioned relevant researches on the coordination of supply chain with uncertain yield and demand and the ideas of literature [18], this paper undertook a research in the case of company-farmer order agriculture into the production decision of the two parties of the supply 
chain targeted at a maximized expected return and put forward a revenue-sharing-plus-margin coordination strategy and gave examples to further analyze the strategy in the premise of uncertain yield and market demand.

\section{Assumptions and Parameters of the Model}

Based upon the Newsvendor model, a company-plus-farmer contract farming supply chain was established in this paper characterized by one company, one smallholder, and one single production cycle. According to this model, the company predicts the market demand for the next sales cycle based on the past sales of agricultural products before the production season and signs an order contract with farmers, clarifying the quantity, quality, and purchase price of agricultural products. Farmers then determine the targeted yield based on the quantity and the purchase price in the contract. After the end of the production cycle of produce, purchase and selling of the produce will be carried out by both parties of the order contract.

\subsection{Assumptions}

(1) It is a supply chain of one company plus one farmer. The information is symmetric between the company and the farmer.

(2) There is only one agricultural product with one production-sale cycle in the supply chain.

(3) The members of the supply chain are risk neutral.

(4) The processing, storage, and transportation costs of agricultural products are not taken into account.

(5) Take into account the company's coping strategy towards the insufficient supply in the contract farming supply chain but not the stock-out cost of farmers.

\subsection{Parameters}

(1) q: the quantity of agricultural products confirmed in the order contract between the company and the farmer.

(2) Q: the targeted yield of certain agricultural product.

(3) $x$ : the random fluctuation factor of the yield; $x \in\left[a_{1}, a_{2}\right]$, the probability density function is $f(\cdot)$, and $E(x)=\mu$ (the expectation of $x$ ). When the targeted yield is $Q$, the actual yield will be $Q x$.

(4) $c$ : the unit production cost of the agricultural product which is related to the targeted yield.

(5) $w$ : the purchase price for the produce.

(6) $h$ : the unit recovery value of the remaining produce that exceeds the agreed amount.

(7) De: market demand, related to sales price and random fluctuation factor; $D e=\alpha p^{-k} y, \alpha$ and $-k$ are constants, $y$ is the random fluctuation factor of market demand, $y \in\left[b_{1}, b_{2}\right]$, and the probability density function is $g(\cdot)$. Let $D=\alpha p^{-k}$; that is, $D e=D y$.
(8) $p$ : sales price for the produce.

(9) $h_{1}$ : the unit recovery value of the unsold produce.

(10) $s$ : unit out-of-stock cost that the company fails to meet market demand.

(11) Without loss of generality, $h<c<w<h_{1}<s<p$.

\section{Production Decision Model and Analysis of Contract Farming Supply Chain}

3.1. Optimal Production Decision of Supply Chain under Centralized Decision-Making. Under centralized decisionmaking, farmers and companies are a whole aiming at maximizing the overall return of the supply chain. In this case, the agricultural products produced by farmers are sold by the company. So here, the total revenue function of the supply chain is

$$
I_{0}=p \min \{D y, Q x\}+h_{1}(Q x-D y)^{+}-s(D y-Q x)^{+}-c Q,
$$

$$
\begin{aligned}
E\left(I_{0}\right)= & p \int_{b_{1}}^{b_{2}} \int_{a_{1}}^{(D y / Q)} Q x f(x) g(y) \mathrm{d} x \mathrm{~d} y \\
& +p \int_{b_{1}}^{b_{2}} \int_{(D y / Q)}^{a_{2}} D y f(x) g(y) \mathrm{d} x \mathrm{~d} y \\
& +h_{1} \int_{b_{1}}^{b_{2}} \int_{(D y / Q)}^{a_{2}}(Q x-D y) f(x) g(y) \mathrm{d} x \mathrm{~d} y \\
& -s \int_{b_{1}}^{b_{2}} \int_{a_{1}}^{(D y / Q)}(D y-Q x) f(x) g(y) \mathrm{d} x \mathrm{~d} y-c Q .
\end{aligned}
$$

According to equation (2), the first and second partial derivatives of $E\left(I_{0}\right)$ with respect to $Q$ can be obtained:

$$
\begin{aligned}
\frac{\partial E\left(I_{0}\right)}{\partial Q}= & p \int_{b_{1}}^{b_{2}} \int_{a_{1}}^{(D y / Q)} x f(x) g(y) \mathrm{d} x \mathrm{~d} y \\
& +h_{1} \int_{b_{1}}^{b_{2}} \int_{(D y / Q)}^{a_{2}} x f(x) g(y) \mathrm{d} x \mathrm{~d} y \\
& +s \int_{b_{1}}^{b_{2}} \int_{a_{1}}^{(D y / Q)} x f(x) g(y) \mathrm{d} x \mathrm{~d} y-c \\
\frac{\partial^{2} E\left(I_{0}\right)}{\partial Q^{2}}= & p \int_{b_{1}}^{b_{2}}\left(-\frac{D y}{Q^{2}}\right) \frac{D y}{Q} f\left(\frac{D y}{Q}\right) g(y) \mathrm{d} y \\
& -h_{1} \int_{b_{1}}^{b_{2}}\left(-\frac{D y}{Q^{2}}\right) \frac{D y}{Q} f\left(\frac{D y}{Q}\right) g(y) \mathrm{d} y \\
& +s \int_{b_{1}}^{b_{2}}\left(-\frac{D y}{Q^{2}}\right) \frac{D y}{Q} f\left(\frac{D y}{Q}\right) g(y) \mathrm{d} y \\
= & -\frac{p+s-h_{1}}{Q^{3}} \int_{b_{1}}^{b_{2}}(D y)^{2} f\left(\frac{D y}{Q}\right) g(y) \mathrm{d} y .
\end{aligned}
$$

$\left(\partial^{2} E\left(I_{0}\right) / \partial Q^{2}\right)<0$ is constant, $E\left(I_{0}\right)$ is the concave function of $Q$, and here $Q^{\prime}$ comes that makes $\max E\left(I_{0}\right)$. Let $\left(\partial E\left(I_{0}\right) / \partial Q\right)=0$, and there is 


$$
\begin{aligned}
& (p+s) \int_{b_{1}}^{b_{2}} \int_{a_{1}}^{\left(D y / \mathrm{Q}^{\prime}\right)} x f(x) g(y) \mathrm{d} x \mathrm{~d} y \\
& +h_{1} \int_{b_{1}}^{b_{2}} \int_{\left(D y / Q^{\prime}\right)}^{a_{2}} x f(x) g(y) \mathrm{d} x \mathrm{~d} y=c .
\end{aligned}
$$

When $c$ increases, $Q^{\prime}$ decreases; that is, when the unit production cost of produce increases, the targeted yield will decrease, which is reasonable.

\subsection{Decentralized Production Decisions by Both Parties of the} Supply Chain. An order contract will be signed by the company and the farmer to specify the amount and the purchase price of agricultural products that are agreed to be produced. Farmers decide the targeted yield of produce and put it into production based on the contract. The farmer then supplies agricultural products to the company after one production cycle and the company sells them to the market. The reverse induction is used for the following analysis. Firstly, we try to analyze the optimum condition for the decision variables to maximize the revenue of the farmer, to clear the relationship between $Q$ and $q$. Secondly, based on the optimum condition, we analyze the decision-making of the company to confirm $Q$. Lastly, $q$ is determined according to the relationship between the two parameters described above.

\subsubsection{Farmers' Production Decisions under Decentralized} Decision-Making. The revenue function under decentralized decision-making is

$$
I_{1}=w \min \{q, Q x\}+h(Q x-q)^{+}-c Q .
$$

In this equation, the first part is the amount paid for farmers by companies purchasing the produce; the second part is the recovery residual value of agricultural products that exceeds the contracted amount; and the third part is the production cost of farmers.

The expected revenue of farmers is

$$
\begin{aligned}
E\left(I_{1}\right)= & w \int_{(q / Q)}^{a_{2}} q f(x) \mathrm{d} x+w \int_{a_{1}}^{(q / Q)} Q x f(x) \mathrm{d} x \\
& +h \int_{(q / Q)}^{a_{2}}(Q x-q) f(x) \mathrm{d} x-c Q .
\end{aligned}
$$

According to equation (7), the first partial derivatives of $E\left(I_{1}\right)$ with respect to $Q$ and $q$ can be obtained:

$$
\begin{aligned}
\frac{\partial E\left(I_{1}\right)}{\partial Q} & =w \int_{a_{1}}^{(q / Q)} x f(x) \mathrm{d} x+h \int_{(q / Q)}^{a_{2}} x f(x) \mathrm{d} x-c, \\
\frac{\partial E\left(I_{1}\right)}{\partial q} & =w \int_{a_{1}}^{(q / Q)} f(x) \mathrm{d} x-h \int_{(q / Q)}^{a_{2}} f(x) \mathrm{d} x \\
& =(w-h) \int_{(q / Q)}^{a_{2}} f(x) \mathrm{d} x .
\end{aligned}
$$

The Hesse Matrix of equation (7) is

$$
\begin{aligned}
H(Q, q) & =\left|\begin{array}{ll}
\frac{\partial^{2} E\left(I_{1}\right)}{\partial Q^{2}} & \frac{\partial^{2} E\left(I_{1}\right)}{\partial Q \partial q} \\
\frac{\partial^{2} E\left(I_{1}\right)}{\partial q \partial Q} & \frac{\partial^{2} E\left(I_{1}\right)}{\partial q^{2}}
\end{array}\right| \\
& =\left|\begin{array}{cc}
-\frac{(w-h) q^{2}}{Q^{3}} f\left(\frac{q}{Q}\right) & \frac{(w-h) q}{Q^{2}} f\left(\frac{q}{Q}\right) \\
-\frac{(w-h) q}{Q^{2}} f\left(\frac{q}{Q}\right) & -\frac{w-h}{Q} f\left(\frac{q}{Q}\right)
\end{array}\right| .
\end{aligned}
$$

Let $A_{1}=\left(\partial^{2} E\left(I_{1}\right) / \partial Q^{2}\right), A_{2}=\left(\partial^{2} E\left(I_{1}\right) / \partial Q \partial q\right), A_{3}=$ $\left(\partial^{2} E\left(I_{1}\right) / \partial q \partial Q\right)$, and $A_{4}=\left(\partial^{2} E\left(I_{1}\right) / \partial q^{2}\right)$, where $A_{1}<0$ and $A_{1} A_{4}-A_{2} A_{3}=\left(\left(2(w-t h)^{2} t q^{2}\right) / Q^{2}\right) f(q / Q)>0$. Therefore, $H(Q, q)$ is negative definite matrix and $E\left(I_{1}\right)$ is strictly concave function and has a unique maximum point $\left(Q^{*}, q^{*}\right)$.

Let equations (8) and (9) be equal to 0 , and the simultaneous equations can obtain $Q^{*}$ (targeted yield) and $q^{*}$ (contracted quantity), satisfying the following equation:

$$
\left\{\begin{array}{l}
\int_{a_{1}}^{\left(q^{*} / Q^{*}\right)} x f(x) \mathrm{d} x=\frac{c-\mu h}{w-h}, \\
(w-h) \int_{\left(q^{*} / Q^{*}\right)}^{a_{2}} x f(x) \mathrm{d} x=0 .
\end{array}\right.
$$

Since the equation $(w-h)>0$ is constant and $(w-h) \int_{\left(q^{*} / Q^{*}\right)}^{a_{2}} x f(x) \mathrm{d} x=0$, we can have $\left(q^{*} / Q^{*}\right) \geq a_{2}$; $q^{*} \geq a_{2} Q^{*}$.

In conclusion, to maximize the expected revenue $E\left(I_{1}\right)$, equation (11) has to be satisfied and $q^{*} \geq a_{2} Q^{*}$.

3.2.2. Company's Order Decision under Decentralized Decision-Making. The revenue function under decentralized decision-making for the company is

$$
\begin{aligned}
I_{2}= & p \min \{q, Q x, D y\}-w \min \{q, Q x\} \\
& -s(D y-\min \{q, Q x\})^{+}+h_{1}(\min \{q, Q x\}-D y)^{+} .
\end{aligned}
$$

To maximize $E\left(I_{1}\right)$, there must be $q^{*} \geq a_{2} Q^{*}$ and $x \in\left[a_{1}, a_{2}\right]$, so we can make $q^{*} \geq Q^{*} x$ constant.

In this case, the revenue function can be transformed into

$$
I_{2}=p \min \{Q x, D y\}-w Q x-s(D y-Q x)^{+}+h_{1}(Q x-D y)^{+} .
$$

The expected revenue function is 


$$
\begin{aligned}
E\left(I_{2}\right)= & p \int_{b_{1}}^{b_{2}} \int_{a_{1}}^{(D y / Q)} \mathrm{Q} x f(x) g(y) \mathrm{d} x \mathrm{~d} y \\
& +p \int_{b_{1}}^{b_{2}} \int_{(D y / Q)}^{a_{2}} D y f(x) g(y) \mathrm{d} x \mathrm{~d} y-w \mu \mathrm{Q} \\
& -s \int_{b_{1}}^{b_{2}} \int_{a_{1}}^{(D y / Q)}(D y-Q x) f(x) g(y) \mathrm{d} x \mathrm{~d} y \\
& +h_{1} \int_{b_{1}}^{b_{2}} \int_{(D y / Q)}^{a_{2}}(\mathrm{Q} x-D y) f(x) g(y) \mathrm{d} x \mathrm{~d} y .
\end{aligned}
$$

According to equation (14), the first and second partial derivatives of $E\left(I_{2}\right)$ with respect to $Q$ are obtained:

$$
\begin{aligned}
\frac{\partial E\left(I_{2}\right)}{\partial Q}= & (p+s) \int_{b_{1}}^{b_{2}} \int_{a_{1}}^{(D y / Q)} x f(x) g(y) \mathrm{d} x \mathrm{~d} y-w \mu \\
& +h_{1} \int_{b_{1}}^{b_{2}} \int_{(D y / Q)}^{a_{2}} x f(x) g(y) \mathrm{d} x \mathrm{~d} y, \\
\frac{\partial^{2} E\left(I_{2}\right)}{\partial Q^{2}}= & (p+s) \int_{b_{1}}^{b_{2}} \frac{D y}{Q} \times\left(-\frac{D y}{Q^{2}}\right) \times f\left(\frac{D y}{Q}\right) \times g(y) \mathrm{d} y \\
& -h_{1} \int_{b_{1}}^{b_{2}} \frac{D y}{Q} \times\left(-\frac{D y}{Q^{2}}\right) \times f\left(\frac{D y}{Q}\right) \times g(y) \mathrm{d} y \\
= & -\frac{p+s-h_{1}}{Q^{3}} \int_{b_{1}}^{b_{2}}(D y)^{2} \times f\left(\frac{D y}{Q}\right) \times g(y) \mathrm{d} y .
\end{aligned}
$$

Since $\left(p+s-h_{1}\right)>0$ is constant, $\left(\partial^{2} E\left(I_{2}\right) / \partial Q^{2}\right)<0$; the expected revenue $E\left(I_{2}\right)$ is a concave function of $Q$, so there is $Q^{0}$ that makes max $E\left(I_{2}\right)$.

Let $\left(\partial E\left(I_{2}\right) / \partial Q\right)=0$; we got

$$
\begin{aligned}
& (p+s) \int_{b_{1}}^{b_{2}} \int_{a_{1}}^{\left(D y / Q^{0}\right)} x f(x) g(y) \mathrm{d} x \mathrm{~d} y \\
& +h_{1} \int_{b_{1}}^{b_{2}} \int_{\left(D y / Q^{0}\right)}^{a_{2}} x f(x) g(y) \mathrm{d} x \mathrm{~d} y=w \mu .
\end{aligned}
$$

From equation (17), we got $Q^{0}=Q^{*}$, and from equation (11), we got $q^{*}$. Obviously, under decentralized decisionmaking, there is a unique Nash equilibrium $\left(Q^{*}, q^{*}\right)$.

Corollary 1. In a supply chain with uncertain yield and demand, the overall expected return under centralized decision-making is no less than that of decentralized decisionmaking.

Proof. When $q^{*} \geq a_{2} Q^{*}$, that is, the maximized revenue for the farmer under decentralized decision-making, since $x \in\left[a_{1}, a_{2}\right], q^{*} \geq Q x$ and the total expected revenue of the company and farmers is

$$
\begin{aligned}
& E\left[I_{1}(\mathrm{Q})\right]+E\left[I_{2}(\mathrm{Q})\right]=p \int_{b_{1}}^{b_{2}} \int_{a_{1}}^{(D y / \mathrm{Q})} \mathrm{Q} x f(x) g(y) \mathrm{d} x \mathrm{~d} y \\
& +p \int_{b_{1}}^{b_{2}} \int_{(D y / Q)}^{a_{2}} D y f(x) g(y) \mathrm{d} x \mathrm{~d} y \\
& \quad-s \int_{b_{1}}^{b_{2}} \int_{a_{1}}^{(D y / Q)}(D y-Q x) f(x) g(y) \mathrm{d} x \mathrm{~d} y \\
& +h_{1} \int_{b_{1}}^{b_{2}} \int_{(D y / Q)}^{a_{2}}(Q x-D y) f(x) g(y) \mathrm{d} x \mathrm{~d} y-c \mathrm{Q} .
\end{aligned}
$$

The expected total revenue of the supply chain under the centralized decision is

$$
\begin{aligned}
E\left[I_{0}(Q)\right]= & p \int_{b_{1}}^{b_{2}} \int_{a_{1}}^{(D y / Q)} Q x f(x) g(y) \mathrm{d} x \mathrm{~d} y \\
& +p \int_{b_{1}}^{b_{2}} \int_{(D y / Q)}^{a_{2}} D y f(x) g(y) \mathrm{d} x \mathrm{~d} y \\
& +h_{1} \int_{b_{1}}^{b_{2}} \int_{(D y / Q)}^{a_{2}}(Q x-D y) f(x) g(y) \mathrm{d} x \mathrm{~d} y \\
& -s \int_{b_{1}}^{b_{2}} \int_{a_{1}}^{(D y / Q)}(D y-Q x) f(x) g(y) \mathrm{d} x \mathrm{~d} y-c Q .
\end{aligned}
$$

Now $\max E\left[I_{1}(Q)\right]+E\left[I_{2}(Q)\right]=E\left[I_{0}(Q)\right]$, so $E\left(I_{1}\right)+$ $E\left(I_{2}\right) \leq E\left(I_{0}\right)$ is constant.

\subsection{Supply Chain Coordination Production Decision Based on} Revenue Sharing plus Margin. In the case of decentralized decision, there must be $q^{*} \geq Q^{*} x$, so there can be $E\left(I_{1}\right)$; namely, the expected revenue of the farmer can be maximized. The revenue function of farmers does not consider the stock-out risk, which means that the actual output of farm products is less than the agreed quantity. As a result, the company will be unable to meet the market demand because of insufficient supply and confronted with high outof-stock costs. Besides, under decentralized decision-making, both farmers and companies will aim to maximize their expected income, which will generate a double marginal effect and reduce the overall benefit of the supply chain.

Therefore, this paper proposes a supply chain coordination strategy based on revenue sharing plus margin, so as to restrain both parties of the contract, reduce the default risk of both parties in the company-plus-farmer mode of order agriculture, and improve the stability of the supply chain. The coordination mechanism of revenue-sharingplus-margin supply chain is as follows:

(1) The company purchases the whole output of agricultural products at the purchase price $w$ in the order contract. 
(2) Farmers enjoy a part of the company's sales revenue, and the income sharing coefficient is $r$, thereby reducing the loss of farmers considering the possibility that the purchase price of agricultural products in the order contract is lower than the sales price.

(3) The technical guidance or financial support from the company is needed in the process of production. Therefore, farmers are supposed to pay a certain amount of margin $M$ to the company as compensation for farmers' wrongdoing.

Under the coordination mechanism of revenue-sharingplus-margin supply chain, the revenue function of the farmer is

$$
I_{1}=w Q x+r p \min \{D y, Q x\}-c Q-M .
$$

The revenue function of the company is

$$
\begin{aligned}
I_{2}= & (1-r) p \min \{D y, Q x\}+h_{1}(Q x-D y)^{+}+M \\
& -s(D y-Q x)^{+}-w Q x .
\end{aligned}
$$

And the total revenue function of the supply chain is

$$
I_{0}=p \min \{D y, Q x\}+h_{1}(Q x-D y)^{+}-s(D y-Q x)^{+}-c Q .
$$

At this point, the total revenue function of the supply chain is consistent with that of the centralized decisionmaking supply chain; that is, the total revenue of the risksharing supply chain achieves the same effect as that of centralized decision-making supply chain. One has

$$
\begin{aligned}
E\left(I_{1}\right)= & w Q \mu+r p \int_{b_{1}}^{b_{2}} \int_{(D y / Q)}^{a_{2}} D y f(x) g(y) \mathrm{d} x \mathrm{~d} y \\
& +r p \int_{b_{1}}^{b_{2}} \int_{a_{1}}^{(D y / Q)} Q x f(x) g(y) \mathrm{d} x \mathrm{~d} y-c Q-M,
\end{aligned}
$$

$$
\begin{aligned}
E\left(I_{2}\right)= & (1-r) p \int_{b_{1}}^{b_{2}} \int_{a_{1}}^{(D y / Q)} Q x f(x) g(y) \mathrm{d} x \mathrm{~d} y \\
& +(1-r) p \int_{b_{1}}^{b_{2}} \int_{(D y / Q)}^{a_{2}} D y f(x) g(y) \mathrm{d} x \mathrm{~d} y \\
& +h_{1} \int_{b_{1}}^{b_{2}} \int_{(D y / Q)}^{a_{2}}(Q x-D y) f(x) g(y) \mathrm{d} x \mathrm{~d} y+M \\
& -s \int_{b_{1}}^{b_{2}} \int_{a_{1}}^{(D y / Q)}(D y-Q x) f(x) g(y) \mathrm{d} x \mathrm{~d} y-w Q \mu .
\end{aligned}
$$

According to equation (5), $Q^{\prime}$ is obtained through equation $E\left(I_{0}\right)$, and with equation (23) as well as equation (24), $E\left[I_{1}\left(Q^{\prime}\right)\right]$ and $E\left[I_{2}\left(Q^{\prime}\right)\right]$ can be obtained.

Since $\left(\partial E\left(I_{1}\right) / \partial r\right)>0, \quad\left(\partial E\left(I_{1}\right) / \partial M\right)<0, \quad\left(\partial E\left(I_{2}\right) / \partial r\right)$ $<0$, and $\left(\partial E\left(I_{2}\right) / \partial M\right)>0$, in other words, the expected revenue of the farmer is the increasing function of $r$ (the revenue-sharing coefficient) and the decreasing function of $M$ (the margin). The expected revenue of the company is a decreasing function of $r$ and an increasing function of $M$.
The expected total return of the revenue-sharing-plusmargin supply chain levels up to that of the centralized decision-making supply chain, and the overall return of the supply chain fulfills Pareto improvement. In addition, under revenue-sharing-plus-margin coordination, the profit coordination between the company and the farmer is mainly achieved by adjusting $r$ (the income sharing coefficient) and $M$ (the margin), and during the course of coordination, the total return under decentralized decision-making mechanism also requires Pareto improvement in order to maintain the stability of company-plus-farmer supply chain.

\section{Example Analysis}

Based on the above deduction and analysis, the example design and result analysis are carried out on the assumption that the random output factor and the market demand fluctuation factor are uniformly distributed. Take the contract farming supply chain consisting of one single agricultural product, one company, and one farmer as an example, and the parameters of the calculation example are shown in Table 1.

MATLAB is used for programming calculation, and the result is shown in Table 2 .

By comparing the numerical results of the example, it can be concluded that the expected revenue of the supply chain under the centralized decision is higher than that of the one under the decentralized decision, realizing the Pareto improvement and also proving the feasibility of revenue-sharing-plus-margin supply chain coordination.

\subsection{Influence of Changes of $r$ (Revenue-Sharing Coefficient) on} the Coordination of the Supply Chain. Make an analysis of the influence of the changes of $r$ (revenue-sharing coefficient) on the revenue coordination and adjust the value of $r$. The results are shown in Table 3 and Figure 1.

It can also be seen from the results of revenue coordination that the expected income of farmers increases with the increase of $r$ (revenue-sharing coefficient), while the expected income of the company decreases on the other hand. Moreover, the expected income of farmers achieves Pareto improvement under the coordinated production decision of the supply chain. When $r \in[0,0.020743]$, the expected income of the company is expected to realize Pareto optimization.

4.2. Influence of the Change of $M$ (Margin) on the Coordination of Supply Chain. Make an analysis of the influence of the changes of $M$ (the margin) on the revenue coordination and adjust the value of $M$. The results are shown in Table 4 and Figure 2.

It can also be seen from the results of revenue coordination that the expected income of farmers decreases with the increase of $M$ (the margin), while the expected income of the company increases on the other hand. Moreover, the expected income of farmers achieves Pareto improvement under the coordinated production decision of the supply 
TABle 1: The basic data of the example.

\begin{tabular}{lccccccccccc}
\hline Parameter & $p$ & $w$ & $c$ & $h$ & $h_{1}$ & $s$ & $D$ & $r$ & $M$ & $x$ & $y$ \\
\hline Value & 12 & 6 & 4 & 2 & 7 & 10 & 100 & 0.0005 & 50 & $x \sim U(0.5,1.1)$ & $y \sim U(0.8,1.3)$ \\
\hline
\end{tabular}

TABle 2: The basic result of the example.

\begin{tabular}{lccccc}
\hline & \multicolumn{2}{c}{ Farmer's decision } & \multicolumn{2}{c}{ Company's decision } & \multirow{2}{*}{ The expected total revenue $E\left(I_{0}\right)$} \\
& $Q$ & $E\left(I_{1}\right)$ & $q$ & $E\left(I_{2}\right)$ & 880.498 \\
Decentralized decision-making & 245.752 & 185.747 & 242.038 & 694.751 & 912.005 \\
Centralized decision-making & 303.441 & 198.659 & - & 713.346 & \\
\hline
\end{tabular}

TABLE 3: The influence of the changes of $r$ on the coordination of the supply chain.

\begin{tabular}{lcc}
\hline$r$ & Expected revenue of the farmer $E\left(I_{1}\right)$ & Expected revenue of the company $E\left(I_{2}\right)$ \\
\hline $0^{*}$ & 192.753 & 719.252 \\
0.005 & 198.659 & 713.346 \\
0.01 & 204.565 & 707.44 \\
0.015 & 210.471 & 701.534 \\
0.02 & 216.377 & 695.628 \\
$0.020743^{*}$ & 217.254 & 694.751 \\
0.025 & 222.283 & 689.722 \\
\hline
\end{tabular}

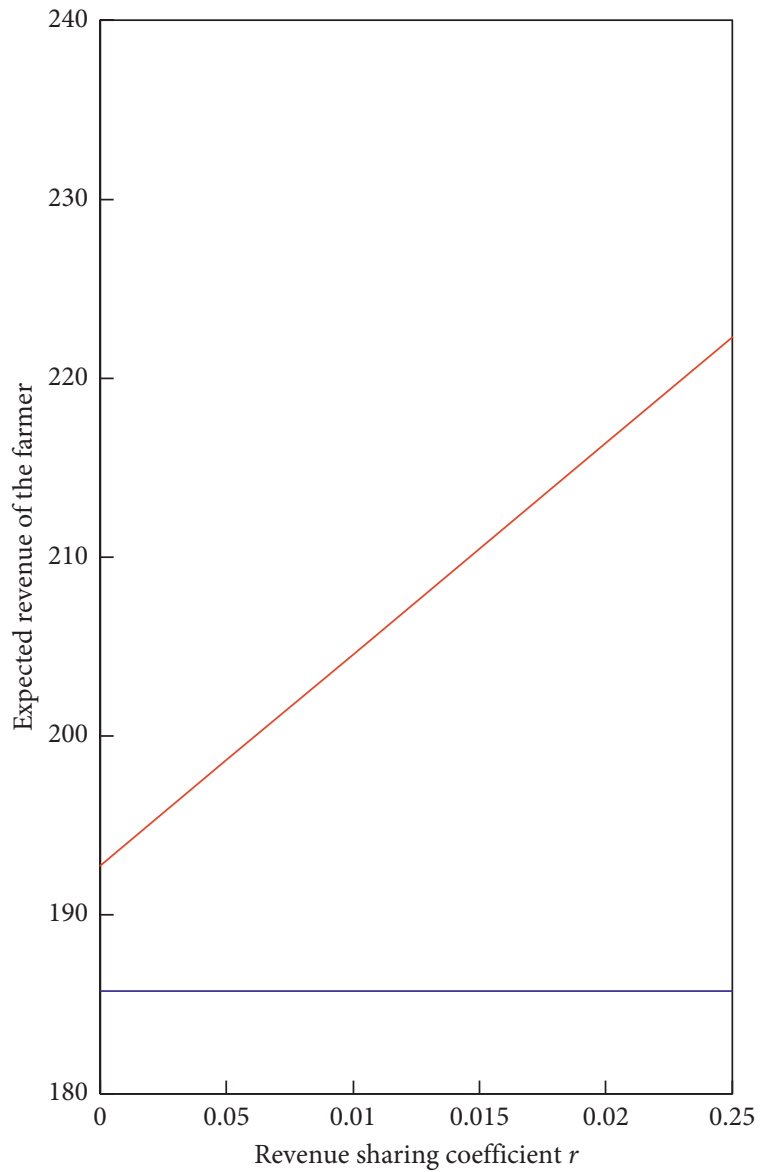

- Centralized decision-making

_ Decentralized decision-making

(a)

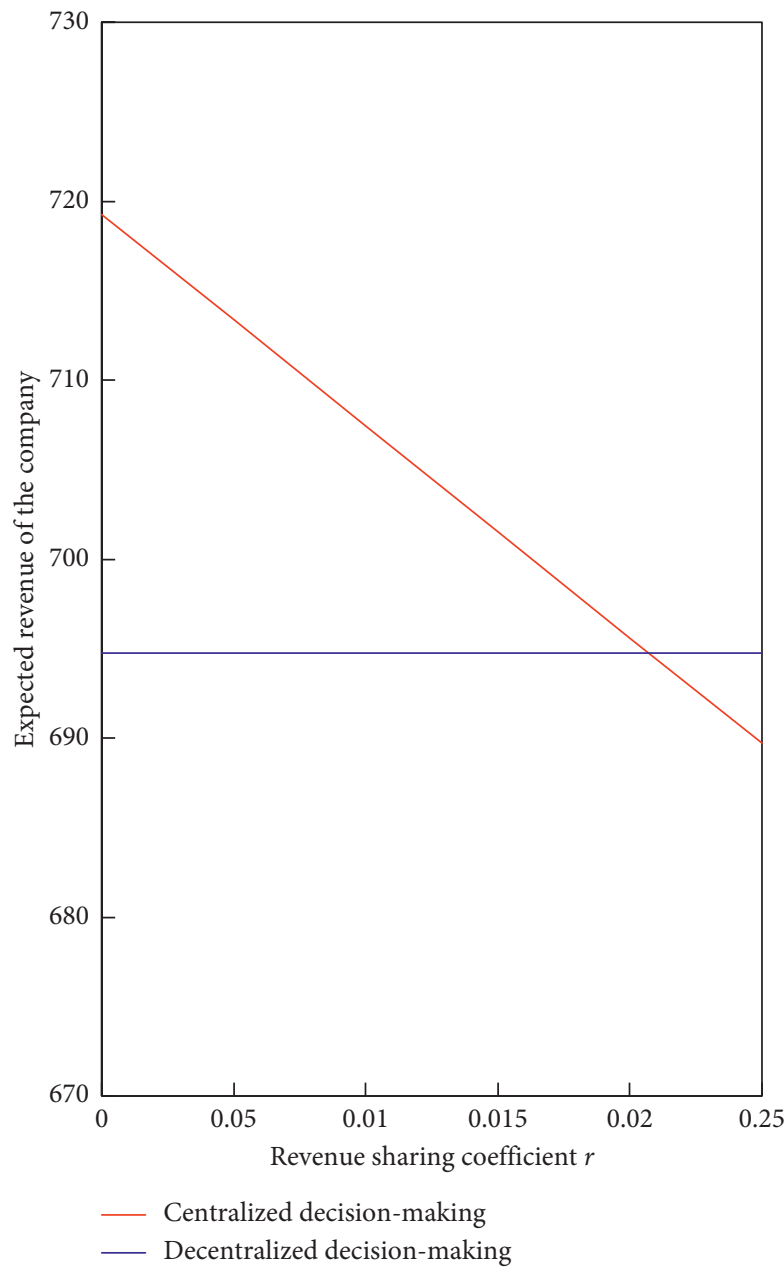

(b)

Figure 1: The influence of the changes of $r$ on the coordination of the supply chain. 
TABLE 4: The influence of the changes of $M$ (the margin) on the coordination of supply chain.

\begin{tabular}{lcc}
\hline$M$ & Expected revenue of the farmer, $E\left(I_{1}\right)$ & Expected revenue of the company, $E\left(I_{2}\right)$ \\
\hline 20 & 228.659 & 683.346 \\
30 & 218.659 & 693.346 \\
$31.405^{*}$ & 217.254 & 694.751 \\
40 & 208.659 & 703.346 \\
50 & 198.659 & 713.346 \\
60 & 188.659 & 723.346 \\
$62.912^{*}$ & 185.747 & 726.258 \\
70 & 178.659 & 733.346 \\
\hline
\end{tabular}

${ }^{*}$ The critical value of the parameter $\mathrm{M}$ when the expected revenue of the farmer and the company reaches the basic value in Table 2.

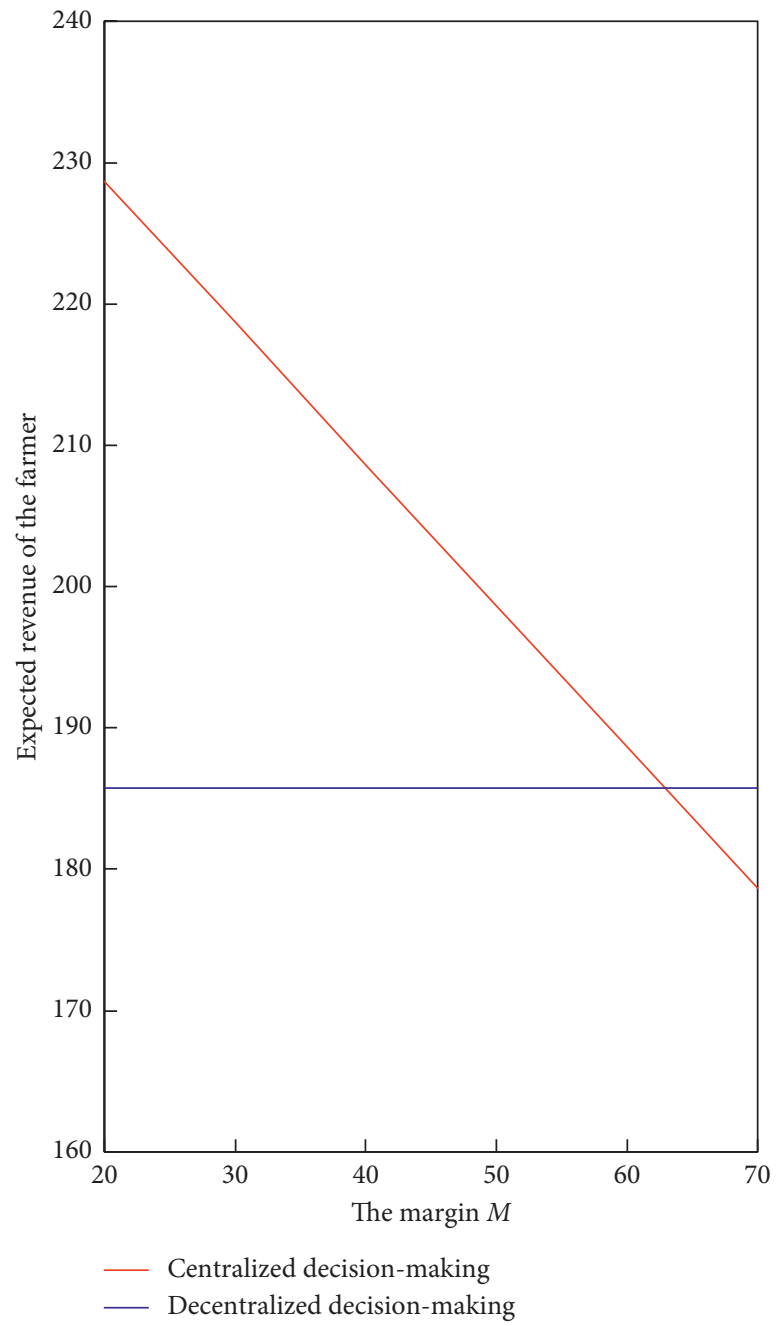

(a)

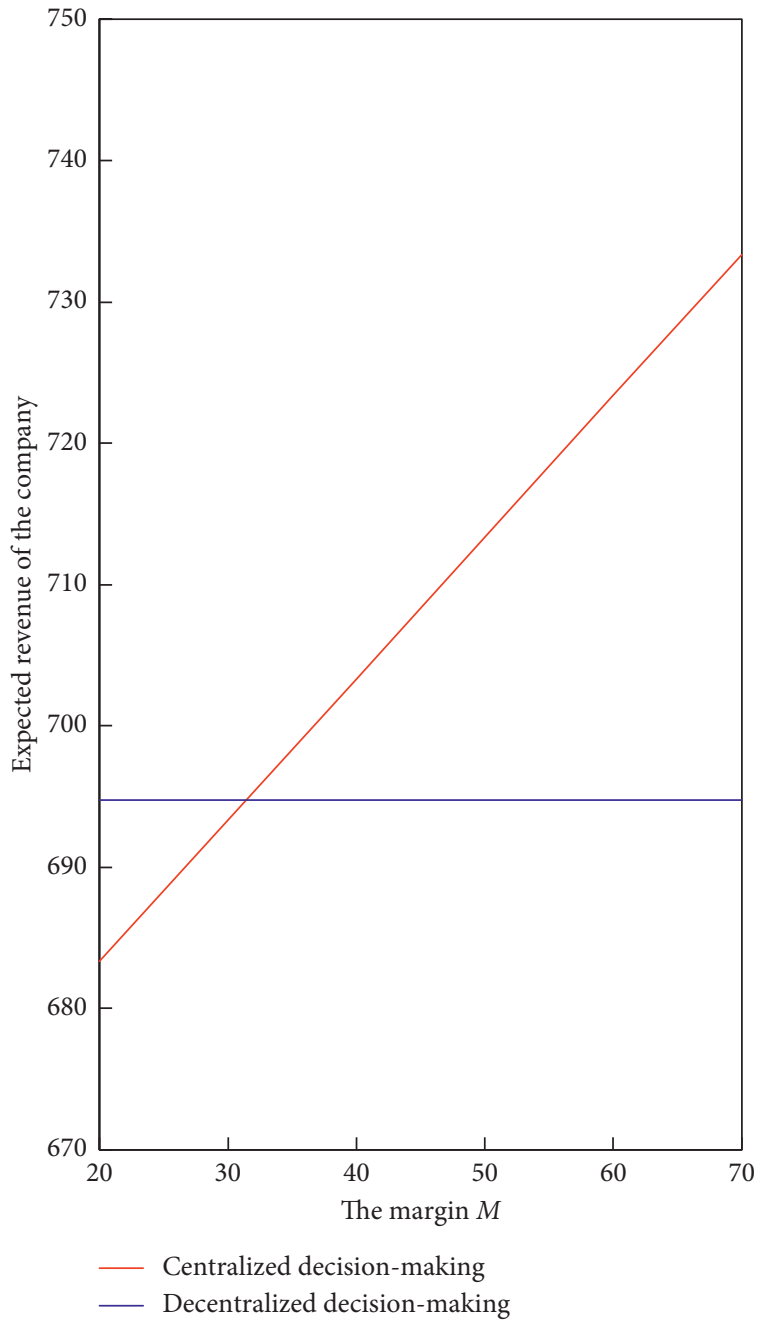

(b)

FIgURE 2: The influence of the changes of $M$ (the margin) on the coordination of supply chain.

chain. When $M \in[31.405,62.912]$, the expected income of both parties is expected to realize Pareto optimization.

Combined with the above analysis, the coordination of the revenue distribution between the company and the farmer can be optimized by adjusting the values of $r$ (income sharing coefficient) and $M$ (the margin) under the coordination mechanism of revenue sharing plus margin in the supply chain. In order to maintain the stability of the supply chain, make sure $r \in[0,0.020743]$ as well as $M \in[31.405,62.912]$, so as to achieve Pareto optimization of both expected revenues. Therefore, it is advisable for companies and farmers to adjust $r$ and $M$ within the range to achieve centralized supply chain overall revenue and Pareto improvement of supply chain coordination under centralized decision. 


\section{Conclusions}

Based upon the Newsvendor model, a company-plus-farmer contract farming supply chain was established in this paper characterized by one company, one smallholder farmer, and one single production cycle. In the case of decentralized decision-making coordination, the expected revenue functions of farmers and of companies were constructed, respectively, and the theoretical analysis showed that there was an optimal range of order quantity and targeted yield to maximize the expected income of farmers. Taking into account both decentralized coordination and centralized production decision-making, the revenue-sharing-plusmargin coordination mechanism of both parties under the centralized decision-making was put forward and proved to be conducive to Pareto improvement in overall revenue of the supply chain, based on theories and calculation examples. And the Pareto optimization of the expected returns of the company and the smallholder farmer in the supply chain coordination of revenue sharing plus margin was discussed by means of examples.

\section{Data Availability}

The data used to support the findings of this study are available from the corresponding author upon request.

\section{Conflicts of Interest}

The authors declare that there are no conflicts of interest regarding the publication of this article.

\section{Acknowledgments}

The research was funded by the Basic Competence Improvement Project for Young and Middle-Aged Teachers in Higher Education of Guangxi (no. 2018KY0341) and the National Natural Science Foundation of China (no. 71462005).

\section{References}

[1] J. E. Hobbs and L. M. Young, "Increasing vertical linkages in agrifood supply chains: a conceptual model and some preliminary evidence," Canadian Journal of Agricultural Economics/Revue Canadienne D'Agroeconomie, vol. 47, no. 4, p. 478, 1999.

[2] S. W. Martinez, "Vertical coordination of marketing systems: lessons from the poultry, egg, and pork industries," Agricultural Economics Report 34051, United States Department of Agriculture, Economic Research Service, Washington, DC, USA,, 2002.

[3] H. Guo and R. W. Jolly, "Contractual arrangements and enforcement in transition agriculture: theory and evidence from China," Food Policy, vol. 33, no. 6, pp. 570-575, 2008.

[4] O. Boyabtli, P. R. Kleindorfer, and S. R. Koontz, "Integrating long-term and short-term contracting in beef supply chains," Management Science, vol. 57, no. 10, pp. 1771-1787, 2011.

[5] G. K. Abebe, J. Bijman, R. Kemp, O. Omta, and A. Tsegaye, "Contract farming configuration: smallholders' preferences for contract design attributes," Food Policy, vol. 40, pp. 14-24, 2013.

[6] F. Liu, "Incomplete contract and performance obstacle-a case study of order agriculture," Economic Research, vol. 49, pp. 22-30, 2003.

[7] J. Liu and C. Qi, "Research on the influencing factors of company-plus-farmer contract: a framework of transaction cost analysis," Economic Latitude, vol. 25, pp. 106-109, 2009.

[8] Z. Wu, X. Huo, and J. Liu, "The stability of farmer-plusleading enterprise contract," Journal of Hebei University of Technology (Social Sciences), vol. 10, pp. 55-57, 2010.

[9] Y. Fang, "Empirical analysis of the management of contract farming default risk by futures market," Agricultural Technology Economy, vol. 30, pp. 97-104, 2011.

[10] Research Group, Xi'an Branch, People's Bank of China, "Logistic empirical study on influencing factors of order agriculture contract performance-based on 381 copies of order contracts from Shaanxi Province," Contemporary Economic Science, vol. 36, pp. 118-128, 2014.

[11] H. Yang, D. Zhang, and H. Wang, "Research on profit sharing in contract farming-based on the analysis of produce price fluctuation and default risk," Theory and Practice of Price, vol. 10, pp. 38-42, 2019.

[12] F. Y. Chen and C. A. Yano, "Improving supply chain performance and managing risk under weather-related demand uncertainty," Management Science, vol. 56, no. 8, pp. 13801397, 2010.

[13] L. Zhen, "Modeling of yard congestion and optimization of yard template in container ports," Transportation Research Part B: Methodological, vol. 90, pp. 83-104, 2016.

[14] L. Zhen, "Tactical berth allocation under uncertainty," European Journal of Operational Research, vol. 247, pp. 928-944, 2015.

[15] Q. Wang, J. J. Li, W. T. Ross Jr., and C. W. Craighead, "The interplay of drivers and deterrents of opportunism in buyersupplier relationships," Journal of the Academy of Marketing Science, vol. 41, no. 1, pp. 111-131, 2013.

[16] X. Zhao and F. Wu, "Research on the revenue sharing contract of agricultural products supply chain coordination under random output and demand," Management Science of China, vol. 17, pp. 88-95, 2009.

[17] L. Ling, Z. Hu, and X. Guo, "Analysis and coordination of farmer-to-supermarket mode under random output and demand," System Engineering, vol. 29, pp. 36-40, 2011.

[18] P. Liu and T. Xie, "Coordination of agricultural products supply chain under random output and demand," Logistics Technology, vol. 32, pp. 381-384, 2013.

[19] G. Sun and L. Xu, "Research on option contracts of produce supply chain under random supply and demand," Journal of Management Engineering, vol. 28, pp. 201-210, 2014.

[20] K. Qin and L. Teng, "Research on oder agriculture supply chain under uncertain conditions," Economic Problems, vol. 2, pp. 111-116, 2016.

[21] X. Tong, "Research on oder agriculture supply chain coordination under uncertain market demand," Technology Economics and Management Research, vol. 4, pp. 67-71, 2018. 